\title{
O MODELO ESCOLAR E A 'VIDA QUE SE VIVE' CONTEMPORÂNEA: INCOMPATIBILIDADE DE GÊNIOS
}

\author{
The School Model and The Contemporary 'Life That One Lives': Incompatibility \\ of two worlds
}

Francisco ESTEFOGO

Faculdade Cultura Inglesa, São Paulo, Brasil Pontifícia Universidade Católica de São Paulo (PUC-SP), São Paulo, Brasil

\begin{abstract}
RESUMO: $O$ presente artigo objetiva discutir a ação de alguns modelos escolares atuais que, frente às novas ordens mundiais no que diz respeito aos avanços tecnológicos e suas mudanças geográficas, sociais e culturais, sobretudo advindas da globalização, normalmente decepcionam ao propiciar ferramentas educativas, culturais e políticas apropriadas, principalmente do ponto de vista linguístico. $O$ modelo escolar de referência tencionado no presente artigo está relacionado com ações docentes que qualifiquem e capacitem os alunos para interagir no mundo de uma forma mais contundente, protagonista e crítica. Como cenário de um modelo escolar, o presente artigo terá como base 3 recortes de um currículo de Língua Inglesa, do ensino fundamental II, da rede pública municipal de uma cidade do interior do estado de São Paulo. A discussão está fundamentada nos aportes teóricos de Santos (2000) no que tange às consequências da globalização, bem como aos conceitos de ação monocultural discutidos por Candau, (2011), de superdiversidade e multiculturalidade, embasados em Vertovec (2007) e Blommaert (2013).
\end{abstract}

PALAVRAS-CHAVE: Ferramentas educativas; Ação monocultural, Superdiversidade, Multiculturalidade

ABSTRACT: The present article aims to discuss the action of some current school models that, in the face of the new world orders regarding technological advances and their geographic, social and cultural changes, mainly due to globalization, usually disappoint when it comes to providing appropriate educational, cultural and political tools, especially from a linguistic point of view. The reference school model intended in this article is related to teaching actions that qualify and enable students to interact in the world in a more forceful, protagonist and critical way. As a scenario of a school model, this article will be based on 3 clippings of an English language curriculum of the municipal public network in the countryside of the state of São Paulo. The discussion is based on the theoretical contributions of Santos (2000) regarding the consequences of globalization, as well as the concepts of monocultural action discussed by Candau (2011), of superdiversity and multiculturality, based on Vertovec (2007) and Blommaert (2013).

KEY-WORDS: Educational tools; Monocultural action, Superdiversity, Multiculturalism 


\section{Introdução}

Este artigo tem como objetivo discutir a ação de alguns modelos escolares atuais que, frente às novas ordens mundiais no que diz respeito aos avanços tecnológicos e suas mudanças geográficas, sociais e culturais, sobretudo oriundas da globalização, normalmente falham ao propiciar ferramentas educativas e culturais adequadas, principalmente do ponto de vista linguístico, como instrumento de interação transformadora, de modo que qualifique e capacite os alunos para interagir no mundo de uma forma mais contundente, protagonística e crítica. Para ilustrar esse cenário, como exemplo de um modelo escolar, o presente artigo terá como base 3 recortes de um currículo de Língua Inglesa, do ensino fundamental II, da rede pública municipal de uma cidade do interior do estado de São Paulo. A ideia é primeiro relacionar o que se pretende ensinar nesse contexto particular, registrado no planejamento curricular apresentado e depois refletir sobre essa proposta de ensino, mesmo nos anos iniciais do estudo da língua inglesa, ante as características da 'vida que se vive' (MARX \& ENGELS, 2006) contemporânea que é tecnológica, frenética, imediatista, complexa, intensa.

Além disso, este estudo também objetiva refletir sobre prospecções de ações docentes e de formação de professores para que essas questões contemporâneas se façam presentes na pauta do ambiente escolar de forma mais veemente. De forma geral, o modelo escolar e a 'vida que se vive' (MARX \& ENGELS, 2006) superdiversa, complexa, multicultural, desigual caminham em direção opostas, o que descaracteriza o papel social da escola como mola propulsora de ascensão social. Já não é de hoje que estudos acadêmicos apregoam, sobretudo no que diz respeito ao ensino de língua inglesa, esse descompasso do perambular da escola com os movimentos céleres do mundo moderno (CELANI, 2001; ESTEFOGO 2001, 2005; LEFFA, 2001, 2002, 2012, 2014, 2016; LIBERALI, 2009, 2012, 2015, 2016; MAGALHÃES, 2001, 2011, dentre outros).

Ademais, este artigo discute questões mais contemporâneas de ordem mundial, sobretudo devido à globalização galopante, que, sob uma perspectiva reflexiva crítica, expande ainda mais o fosso entre a escola e o mundo. Os avanços deste artigo estão relacionados às perspectivas de Santos (2000) no que diz respeito às consequências da globalização, bem como aos conceitos de ação monocultural (CANDAU, 2011), superdiversidade (VERTOVEC, 2007; BLOMMAERT, 2013) e multiculturalidade (VERTOVEC, 2007).

Dada a nova ordem de constituição, organização, estruturação e do movimento célere do mundo contemporâneo, esses conceitos deveriam conviver de mãos dadas com a ação escolar para que os artefatos culturais, sobretudo a linguagem, e em particular o ensino da língua inglesa, veículo de comunicação contemporâneo das artes, economia, cultura, política mundial, dentre outras esferas, pudessem ser trabalhados 
dentro dos muros da escola de forma adequada, atual e pertinentes. Assim, a priori, os alunos estariam capacitados, habilitados e qualificados para terem mobilidade social e então realizar, participar, expandir, mudar, questionar, transformar as novas atividades humanas impingidas por um mundo cada vez mais complexo, multidiverso e multicultural, cenário oriundo da arrebatadora globalização.

Este artigo está organizado primeiro, a partir do conceito da 'vida que se vive' de Marx \& Engels (2006), ou seja, o ponto de partida da ciência é a própria vida, o que de fato vivemos no dia a dia, sem interpretações ou abstrações elucubradas. $\mathrm{Na}$ sequência, o conceito de globalização (SANTOS, 2001), com seus movimentos, consequências e com suas particularidades superdiversas (VERTOVEC, 2007; BLOMMAERT, 2013) e multiculturais (VERTOVEC, 2007) será discutido.

Posteriormente, há a discussão de um modelo escolar, baseada em 3 recortes de um currículo de Língua Inglesa, do ensino fundamental II, da rede pública municipal de uma cidade do interior do estado de São Paulo. As considerações finais são tecidas na subsequência.

\section{A 'vida que se vive' contemporânea}

Movimento dominante, intercontinental, impositivo, competitivo e impessoal às vezes perverso e confuso para Santos (2000) -, além de ser veloz e intenso, que atravessa - em alguns casos, assola-as sociedades contemporâneas, a globalização rompe fronteiras - pelos menos, as fronteiras fisicas - nacionais e internacionais, integra e conecta as comunidades (algumas) sincronicamente, transformando o mundo numa verdadeira aldeia superdiversa. A revolução tecnológica centrada em torno das tecnologias de informação, telecomunicação e transporte que se fortaleceu nas últimas décadas, a interdependência das economias à escala global que introduziu uma nova forma de relação entre as economias mundiais, os governos e as sociedades são alguns dos acontecimentos históricos que frequentemente têm transformado a paisagem social da vida humana. Como consequência, o mundo é verdadeiramente multicultural, multidiverso, confuso e complexo, além de ser interdependente que somente pode-se compreender e tentar mudá-lo a partir de uma perspectiva plural que articule identidade multicultural, interconexão global e política multidimensional. Além disso, as relações entre os sujeitos e as instituições, sejam elas de natureza econômica, política ou cultural, tendem a desvincular-se das contingências e limites do espaço. Portanto, a globalização não é um fenômeno puramente econômico e tecnológico, mas um processo complexo, multicultural, multidimensional que envolve as sociedades mundiais, num plano macro e afeta individualmente os diversos âmbitos da vida que se vive (MARX \& ENGELS, 2006) contemporânea. Dentre outros efeitos, para Santos (2000), a competitividade, impingida pela globalização, impõe de maneira totalitária a forma de se viver, de um jeito homogêneo:

A competitividade, sugerida pela produção e pelo consumo, é a fonte de novos totalitarismos, mais facilmente aceitos graças à confusão dos espíritos que se instala. Tem as mesmas origens a produção, na base 
mesma da vida social, de uma violência estrutural, facilmente visível nas formas de agir dos Estados, das empresas e dos indivíduos. A perversidade sistêmica é um dos seus corolários. Os fatores que contribuem para explicar arquitetura da globalização atual são: a unicidade da técnica, a convergência dos momentos, a cognoscibilidade do planeta e a existência de um motor único na história, representado pela mais-valia globalizada. Um mercado global utilizando esse sistema de técnicas avançadas resulta nessa globalização perversa (SANTOS, 2000: 12)

Dado o cenário mundial contemporâneo, urge que se reflita, mais do que nunca, sobre como a ação escolar articula essas peculiaridades das sociedades modernas nas práticas docentes do dia a dia, no planejamento curricular, bem sobre o tipo de aluno que a escola está formando para interagir de forma protagonistica na vida que se vive (MARX \& ENGELS, 2006), que está bem diferente de apenas 5 anos atrás. Sabe-se que a escola tem uma ação monocultural (CANDAU, 2011), ou seja, sem condutas docentes que aflorem novas forças sociais, políticas e culturais num mundo cada vez mais complexo, multidiverso e multicultural. Em particular, no que tange o ensino de línguas, o foco normalmente é em aspectos meramente gramaticais, estruturais, sem contexto e conexão com a vida que se vive (MARX \& ENGELS, 2006). Isso poderá ser evidenciado a frente, com os modelos de currículos de ensino de língua inglesa que serão apresentados de uma rede municipal do ensino fundamental II.

À medida que o mundo moderno se torna mais complexo, mais multidiverso, multicultural, e fluído, teoricamente sem as barreiras físicas - para algumas comunidades -, urge a necessidade de se refletir sobre a essência interior do sujeito, que constitui sua identidade. O sujeito não é autônomo e autossuficiente, mas é constituído como sujeito com outras pessoas que lhe mediam os valores, língua e símbolos - a cultura, principalmente pela e na escola. Numa concepção sociológica do sujeito, podese afirmar que sua identidade é formada na interação entre o sujeito e a sociedade. Para Marx, o sujeito faz história nas relações sociais com o outro, mas não numa noção abstrata do sujeito no centro de seu sistema teórico, o que invalida qualquer noção de agência individual na sua constituição. A globalização inegavelmente tem um efeito pluralizante sobre as identidades, produzindo uma variedade de possibilidades e novas posições de identificação, tornando as identidades menos fixas e unificadas. As identidades são multiversas também. E como está a identidade da escola frente a essa volatilidade de identidades? De modo geral, com ações docentes retrógradas, com raras exceções.

As sociedades globalizadas multidiversas colocam em cheque os seus aspectos regionais, culturais, linguísticos, por não serem mais estáticos, isolados, determinantes. O mundo está mais fluído, no entanto mais confuso. Além da revolução tecnológica, de telecomunicação e de locomoção, o que a priori possibilita maior mobilidade, esse 
processo tem se intensificado com os movimentos migratórios que o mundo tem assistido nos últimos anos. As línguas, os valores, os costumes e as culturas, dentre outros aspectos, têm se fundido numa vertente complexa de um pensamento único que impõe certos desafios para algumas instituições sociais, sobretudo a escola. A escola poderia ser uma instituição que provesse ferramentas para se entender melhor essa confusão. Nas palavras de Santos (2000:23), esse desalinho de pensamentos oriundos da globalização pode ser mais bem explicado:

neste mundo globalizado, a competitividade, o consumo, a confusão dos espíritos constituem baluartes do presente estado de coisas. A competitividade comanda nossas formas de ação. O consumo comanda nossas formas de inação. E a confusão dos espíritos impede o nosso entendimento do mundo, do país, do lugar, da sociedade e de cada um de nós mesmos, (SANTOS, 2000:23).

Esse amálgama de variáveis que afeta como, onde e com quem as pessoas vivem é definido por Vertovec (2007) como superdiversidade. O referido autor entende por superdiverso, ou superdiversidade, os inconstantes aspectos oriundos dos movimentos sócio-históricos instáveis que influenciam a maneira como as pessoas interagem, vivem, se relacionam, se movimentam. De forma mais ampla, para o referido autor, a superdiversidade é a diversidade dentro da diversidade. A superdiversidade ocasiona imprevistos, mais zonas de desconforto, tensões, aleatoriedade, imprevisibilidade, turbulências sociais. Circunstâncias adversas que poderiam fazer pauta da prática escolar para, baseada na argumentação (LIBERALI, 2013), serem instrumentos inspiradores para a construção de novos conhecimentos.

Apesar da perversidade e confusão de espíritos apontada por Santos (2000), dentre os benefícios da fluidez de valores culturais, econômicos, sociais e políticos, para Burbules e Torres (2004), "a globalização está associada a um padrão de vida mais elevado" devido à maior possibilidade do engrandecedor contato com culturas diferentes, modos de vida, tecnologia avançadas, modos de produção de vanguarda, de novos conhecimentos, de desenvolvimento. Certamente, essa mobilidade só é possível para alguns grupos que dispõem de recursos para poder ter acesso a essa profusão de elementos que a globalização propicia. No entanto, os menos abastados não desfrutam das benesses desse movimento dominante, intercontinental, impositivo e impessoal por terem recursos limitados, ou às vezes, por não terem minimamente meios de sobreviver de uma forma digna, decente, por não terem direito a voz. O que poderia amenizar esse poder de mobilidade, que é restrito às comunidades com mais recursos, dentre outras ações, seria uma prática pedagógica mais libertadora, provedora de instrumentos de ação ativa na sociedade, de espaços para a ascensão social mais democrática. A conduta monocultural (CANDAU, 2011) da escola na verdade reforça e perversidade da 
globalização, apontada por Santos (2000), pois com o status quo mantido, não há chances de emergir novas forças na sociedade. Os que a tem, continuam tendo cada vez mais; os que não, como um modelo escolar monocultural (CANDAU, 2011), terão menos chances ainda de serem protagonistas, pois não terão forças sociais, linguísticas, de repertório e mobilidade social para se posicionarem frente à realidade.

No entanto, na contramão dessa ordem multidiversa mundial, a escola que poderia ser uma forte aliada na distribuição das vantagens da globalização, se não derrubar os seus muros castradores, legitimando o poder disciplinador, normalmente atua como reguladora das vidas, das atividades, do trabalho, dos prazeres do indivíduo (que tem dinheiro), sob astuto controle e disciplina, com saberes encapsulados (LIBERALI, 2015, 2016) com base nos regimes administrativos, que mantém o status $q u o$, não fomentando situações que poderiam empoderar os mais reprimidos. A escola deveria estar à frente da luta da horizontalidade dos oprimidos contra a verticalidade dos opressores.

A prática pedagógica não está isenta das complexidades e dos aspectos políticos e socioeconômicos do cenário mundial globalizado, multicultural (VERTOVEC, 2007) e superdiverso (VERTOVEC, 2007; BLOMMAERT, 2013) que, mais do nunca nos dias de hoje, norteiam a sociedade devido à revolução tecnológica e de mobilidade, sobretudo. Essas situações, uma vez reconhecidas, respeitadas e incorporadas pelos partícipes da atividade não oportunizam os binarismos individuais, mas permitem que, por intermédio da língua(gem) e do contexto sócio-histórico, condições para que as diversidades possam ser vivenciadas. A escola deve estar pronta para vivenciar a superdiversidade com, por exemplo, materiais de ensino apropriados, recursos didáticos, professores atuando como agentes críticos transformadores, conscientes do seu papel político, dentre outras possíveis ações dentro da escola. Além disso, os alunos também devem atuar como agentes de transformação, dada a riqueza ímpar de cada história de vida. Dessa forma, se ação pedagógica for desenvolvida dentro da concepção multicultural da sociedade globalizada, na sala de aula, por exemplo, a ação pedagógica a priori utilizará uma variedade de estilos de diversos processos de ensinoaprendizagem em consonância com a diversidade de convenções dos vários grupos étnicos e culturais da comunidade, propiciando mais espaços para que a diversidade possa ser discutida, respeitada vivenciada e consequentemente a criatividade possa ser aguçada, construída. Além disso, Liberali (2012) discute o ensino de língua estrangeira a partir da estruturação da matriz curricular sob o viés das esferas sociais em que as pessoas vivem, bem como 'pelos anseios de participação social que têm', (LIBERALI, 2012:23). Em outras palavras, a autora sugere que o ensino de língua estrangeira seja feito por meio das Atividades Sociais, pois assim há espaços para a reprodução da situação social real não acessível ao aluno, de modo que a torne mais penetrável e possível para se vivenciar e experimentar esse cenário social por intermédio dos instrumentos discursivos linguísticos da língua alvo. Nas palavras de Liberali (2016): 


\begin{abstract}
A atividade social é aqui vista como organizadora curricular central que tem a finalidade de atravessar as barreiras entre a escola e a vida e permitir que os aprendizes estabeleçam relações entre o que aprendem e o que a vida demanda para a sua participação plena (LIBERALI, 2016:19).
\end{abstract}

Além disso, Liberali (2016) também discute a organização de uma matriz curricular estruturada a partir das Atividades Sociais com uma visão de multiletramentos. Essa concepção, que se esmera na diversidade de ideias (multiculturalidade), na maneira de evidenciar os acontecimentos (multimodalidade) e de instrumentos culturais (multimídias), contribui na organização didática da matriz curricular. Dessa forma, o currículo estará pautado em múltiplas maneiras de compreender e conceber o mundo, com modos de participação com uma oferta de bases analíticas e críticas de modo que os alunos possam fazer "escolhas e tomar decisões sobre quem são elou querem ser, que atitudes e modos de agir preferem ou podem assumir e por que" (LIBERALI, 2016:19). Entende-se assim que modelo escolar pode oferecer ferramentas linguísticas, sobretudo, para que a 'vida que se vive' (MARX \& ENGELS, 2006) contemporânea possa de ser de fato vivenciada, transformada.

Para o $7^{\circ}$ ano, por exemplo, Liberali (2012) sugere as seguintes atividades sociais: fazer passeios (museu, parque, zoológico etc.), fazer compras, ler revistas em quadrinhos, dentre outras. Conhecer outras culturas (pela Internet), discutir problemas com amigos, assistir a filmes, dentre outras, são sugestões de atividades sociais feitas por Liberali (2012) para o $9^{\circ}$ ano. Percebe-se que são situações rotineiras da vida que se vive (MARX \& ENGELS, 2006) dos alunos dessas faixas etárias.

É urgente que a escola incorpore a dimensão cultural na prática pedagógica. Por uma escola mais democrática, âmbito das multivozes e identidades culturais diversas, há a premente necessidade de uma articulação entre as práticas pedagógicas e perspectiva multicultural da contemporaneidade (CANDAU \& ANHORN, 2012). A escola deve "reconhecer a força dessas tendências [contemporâneas, globalizadas, superdiversas] e enxergar as suas implicações para moldar e limitar as escolhas disponíveis de políticas e práticas educacionais enquanto também resistem à retórica da 'inevitabilidade que frequentemente motiva a prescrição de certas políticas”, (BURBULES \& TORRES, 2004:11). O não enfrentamento dessa questão das diferenças pela e na ação educativa caracteriza a escola, como já citado previamente, numa perspectiva monocultural (CANDAU, 2011). Essa compreensão, na verdade, advém da visão positivista de educação que entende o conhecimento "como resultante da pesquisa, desenvolvida por alguém que não o professor, dentro de rigorosos padrões científicos, generalizável e aplicável a qualquer situação" (CELANI, 2001:26). Para Freire (2003), essa visão simplista e homogênea da educação subestima o sujeito e impermeabiliza a investigação 
para os contextos reais da vida, na vida que se vive (MARX \& ENGELS, 2006). Numa perspectiva mais ampla no que se refere ao papel político do professor, os conteúdos escolares focados num viés conteudista apenas, num viés top-down do conhecimento, não abrindo espaço para discussão, do preconceito, da discriminação e dos grupos minoritários, dos menos abastados, dos imigrantes, dos oprimidos, dos religiosos, dos homossexuais, dentre outros, caracteriza a visão monocultural e unilateral da escola em relação ao mundo superdiverso, fora dos muros escolares, como daltonismo cultural (CANDAU, 2011). Santos (2000:21) define a homogeneidade imposta pelo consumo exacerbado do capitalismo como:

\begin{abstract}
Aldeia global tanto quanto espaço-tempo contraído permitiria imaginar a realização do sonho de um mundo só, já que, pelas mãos do mercado global, coisas, relações, dinheiros, gostos largamente se difundem por sobre continentes, raças, línguas, religiões, como se as particularidades tecidas ao longo de séculos houvessem sido todas esgarçadas. Tudo seria conduzido e, ao mesmo tempo, homogeneizado pelo mercado global regulador (SANTOS, 2000:21).
\end{abstract}

Essa concepção daltônica e monocultural (CANDAU, 2011), além de ofuscar a atuação da escola da subversão dos contextos superdiversos, repletos de zonas de desconforto e diferenças sociais, caracteriza o professor como um instrutor que não incita a criatividade que pode advir da diversidade cultural, mas apenas o principal agente técnico no processo de ensino-aprendizagem no que se refere ao 'conhecedor e dono do conteúdo'; quanto ao aluno, ele é um agente passivo que, na concepção bancária de ensino (FREIRE, 1970), apenas recebe e reproduz o depósito de todo conhecimento transmitido pelo professor e se conscientiza de forma bancária também (FREIRE, 2003), potencializando a visão monolíngue, míope e unidirecional da ação da escola. Um processo de ensino que mantém o status quo. Uma ação pedagógica que comunga com preceitos do mercado capitalista regulador homogeneizado. $\mathrm{O}$ daltonismo da escola não abre espaços para que a diversidade cultural possa ser reconhecida $-e ́$ fato -, discutida e certamente, respeitada. Não se propicia espaços para que novas ferramentas sociais sejam compartilhadas em busca de uma vida mais digna, de direitos e vozes, principalmente dos reprimidos, menos abastados, com poucas chances de fazer parte ativamente do mundo globalizado. Da maneira como normalmente a escola atua, os desafortunados de participar desse processo dominante, intercontinental, impositivo e impessoal e confuso estão à margem, sem forças e ferramentas de laboração, ficando ainda mais distantes das chances de desenvolvimento e ascensão social que a globalização teoricamente propicia.

Essa visão de monocultural da educação, infelizmente, onde o professor ensina e o aluno aprende, é também tida pela maioria dos cursos de graduação de formação de professores e pelos próprios professores em formação pré-serviço (na verdade, muitos 
professores em serviço também têm essa visão, tampouco consciência, de ensinoaprendizagem e do papel monocultural (CANDAU, 2011) da escola. Muitos não têm essa consciência desenvolvida no que diz respeito ao mundo superdiverso globalizado, pois não fizeram - nem fazem nas várias atividades pedagógicas - parte de atividades durante a formação docente que se discutissem essas questões). Isso tudo é resultado de um paradigma da educação tradicional que há anos perdura no país. Não são surpreendentes as falidas propostas pedagógicas das escolas, o preparo inadequado dos professores e a formação deficiente dos alunos que deixam a escola, pois, na maioria das vezes, tanto os professores, como os alunos e outros agentes da educação têm a mesma compreensão da educação: "o professor sabe, o aluno não sabe o professor ensina, o aluno aprende" (FREIRE, 1970:59); o professor é o agente ativo no processo de ensino-aprendizagem e o aluno é o passivo. Não é surpreendente a ineficiência da escola como agência catalisadora de transformações, ascensão social mais democrática e acolhimento das "identidades culturais, de suas particularidades e contribuições específicas à construção social", (CANDAU \& ANHORN, 2012).

$\mathrm{Se}$ os aspectos relacionados ao processo de ensino-aprendizagem são trabalhados da forma plastificada acima descrita, o que se dirá das questões políticas, sociais, culturais que são inerentes à prática docente? É importante que se propicie um ambiente de reflexão crítica (LIBERALI, 2000, 2004, 2009, 2015, 2016) para que o professor se conscientize da natureza social, cultural e política da prática docente, e aja como um agente crítico transformador. Urge que se elimine a miopia que cega as práticas pedagógicas da realidade caótica e multicultural que a vida é de fato, repleta de desordem, afora os muros e fronteiras da escola, ou as fronteiras de a globalização ainda não deu conta de extirpar.

Dado o atual contexto da educação, é necessário, dentre outras possíveis ações, que se formule um programa de formação de professores que leve em consideração as questões acima descritas, que envolvam a reflexão, a criticidade, que valorize a superdiversidade da contemporaneidade e o compromisso com a educação mais democrática, como agência transformadora. É necessário que a educação seja uma vertente de ações que envolva a participação dos alunos. Nesse sentido, Garcia e Flores (2012) discutem as pedagogias multilíngues como centrais nos processos educativos que incluem a participação ativa dos alunos. Para que esses tipos de pedagogias possam ser desenvolvidos, os referidos autores chamam a atenção para a justiça e a prática social, uma vez que os grupos sociais se posicionam de forma diferente numa comunidade. Assim sendo, as pedagogias multilíngues, com um viés crítico, possibilitariam o desenvolvimento do pensamento crítico dos alunos para que os cenários de injustiça e desigualdade tivessem mais chances de transformação. Em espaços escolares mais democráticos, a participação dos alunos, com suas idiossincrasias culturais, linguísticas, sociais, teriam mais possibilidades de gerar equidade para todos. Além disso, o desenvolvimento da consciência multilíngue e da 
tolerância seria construído a partir das potencialidades culturais e linguísticas de cada um. Ainda nas pedagogias multilíngues, a ação pedagógica seria um instrumento para que se pudesse compreender - e participar das - as forças culturais, sociais, políticas e econômicas da sociedade.

Em situações mais particulares da prática pedagógica, Ferreira (2014) faz uma crítica aos livros didáticos, sobretudo de língua estrangeira, que privilegiam algumas identidades sociais, como gênero, sexualidade, classe social, raça, ideologia, raça, sobretudo pessoas brancas, heterossexuais e da classe média.

Os livros didáticos estão a todo o momento enviando mensagens, ou seja, o currículo oculto atuando, que, de uma forma ou de outra, privilegiam um perfil hegemônico de sociedade, perfil que faz pensar que somente pode ser 'bem-sucedido', estar representados nos livros didáticos e fazer parte da sociedade brasileira quem for branco, heterossexual e de classe média alta (FERREIRA, 2014: 113).

Para a autora, o professor deve refletir sobre essas questões homogêneas da ação humana para que se possa analisar esse material com o intuito de encontrar outras possibilidades para as suas necessidades, levando em consideração a superdiversidade cultural de suas realidades locais. Dessa forma, as ações pedagógicas estão voltadas $a$ priori para um viés de valorização das diferentes formas de viver e ser dos sujeitos. Certamente, outras práticas pedagógicas podem ser discutidas e implementadas com esse intuito de abarcar essas questões que a superdiversidade impinge, no sentido de que a prática docente transcenda as fronteiras - ou as deixem mais porosas - que a globalização, mesmo com revolução tecnológica, de telecomunicação e de locomoção, ainda insiste em manter em pé.

\section{Modelo escolar}

A incompatibilidade de ação condizente do modelo escolar com o mundo frenético e célere que ocorre além dos muros da escola é evidenciada neste artigo com 3 exemplos de recortes de currículos escolares de língua inglesa, do ensino fundamental II, da rede municipal de escolas de uma cidade do interior de São Paulo. Mais especificamente, partes do currículo do $5^{\circ}, 7^{\circ}$ e $9^{\circ}$ ano. A ideia dessa escolha é para evidenciar o que se 'aprende' no começo, no meio e ao final desse ciclo. Também é um instrumento de reflexão frente o ensino-aprendizagem de língua inglesa a partir das Atividades Sociais, como discutidas por Liberali (2012) acima.

A rede oficial de escolas desse município conta com 55 unidades. Em média, os alunos dessa fase começam a estudar aos 9 anos e terminam aos 14. O sistema de ensino atual é o modelo adotado em observância à Lei de Diretrizes e Base da Educação. 
Segundo o estatuto da secretaria municipal da educação dessa cidade, nesse período, são proporcionadas ao aluno possibilidades educativas ao mundo das letras, para que tenha o pleno domínio da leitura e da escrita, do cálculo e do raciocínio. No entanto, não é isso que se evidencia quando os currículos são analisados.

Baseado nos modelos de currículos a seguir apresentados, o foco do ensino pode ser evidenciado pelo seu aspecto estrutural, gramatical, sem contexto. Isso pode ser observado nas séries iniciais do ensino de língua inglesa, ou seja, no $5^{\circ}$ ano e mesmo ao final do ensino fundamental II, isto é, no $9^{\circ}$. Os alunos ficam 5 anos meramente sendo expostos a alguma parte do sistema da língua inglesa, sem relação com a superdiversidade, complexidade e multiculturalidade da vida que se vive (MARX \& ENGELS, 2006) contemporânea.

A seguir, um recorte do $3^{\circ}$ bimestre do $5^{\circ}$ ano:

\begin{tabular}{|c|c|c|}
\hline & $\begin{array}{l}\text { CONTEÚDOS DO } 5^{\circ} \text { ANO } \\
\text { LÍNGUA INGLESA }\end{array}$ & HABILIDADES \\
\hline 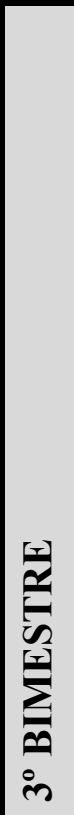 & $\begin{array}{l}\text { GRAMÁTICA: } \\
\text { - Artigos definidos e } \\
\text { indefinidos. } \\
\text { VOCABULÁRIO: } \\
\text { - Móveis e partes da } \\
\text { casa; } \\
\text { - Utensílios de cozinha; } \\
\text { - Comidas (café da } \\
\text { manhã, almoço, lanche } \\
\text { e jantar) e bebidas; } \\
\text { - Frutas. } \\
\text { GÊNERO DISCURSIVO: } \\
\text { - Receita Culinária. }\end{array}$ & $\begin{array}{l}\text { Ao final do } 3^{\circ} \text { bimestre, espera-se que o aluno } \\
\text { consiga: } \\
\text { - Expressar preferências sobre comidas e bebidas, } \\
\text { comparando-as com características de café da } \\
\text { manhã, almoço, lanche e jantar em outras regiões } \\
\text { do Brasil e outros países; } \\
\text { - Nomear utensílios domésticos usados para } \\
\text { preparar alimentos e durante as refeições; } \\
\text { - Nomear móveis e partes da casa; } \\
\text { - Nomear frutas; } \\
\text { - Utilizar os artigos com o vocabulário trabalhado; } \\
\text { - Reconhecer receitas culinárias simples e localizar } \\
\text { o vocabulário trabalhado. }\end{array}$ \\
\hline
\end{tabular}

Como pode ser visto, o foco se concentra em itens lexicais apenas, pois tanto na coluna de 'conteúdos' como de 'habilidades', percebe-se que se ensina uma lista de vocabulários, palavras soltas, e depois como ação comunicativa, os alunos 'nomeiam', ou apenas localizam esses objetos e afins. Fica claro não que não há correlação nenhuma com a vida que se vive (MARX \& ENGELS, 2006) contemporânea de uma criança com em média 9 anos. Nessa fase, andam de bicicleta, gostam que revistas em quadrinhos, brincam com carrinhos, bonecas, gostam de fazer vídeos, fazem piquenique, dentre outras atividades. No caso do recorte acima, talvez o trabalho com os 
itens lexicais relacionados às comidas e bebidas, por exemplo, pudessem ser contextualizados numa atividade de fazer um piquenique com frutas e outros tipos de alimentos. Além disso, como desenvolvimento de gênero discursivo, ou seja, a receita culinária, pode-se afirmar que há uma incongruência com as habilidades trabalhadas, pois nem todos os itens sugeridos compõem linguística e discursivamente o gênero escolhido. Nota-se, portanto, pelos dados apresentados acima, que o currículo não propicia ferramentas linguísticas para se tratar da superdiversidade (VERTOVEC, 2007), complexidade e multiculturalidade da vida que se vive (MARX \& ENGELS, 2006) contemporânea.

Na sequência, um recorte do $1^{\circ}$ bimestre do $7^{\circ}$ ano: 
CONTEÚDOS DO $7^{\circ}$ ANO DE LÍNGUA INGLESA

\section{HABILIDADES}

\section{GRAMÁTICA:}

- Presente simples (formas afirmativa, negativa e interrogativa);

- Advérbios de frequência;

- Verbo to be - presente (formas afirmativa, negativa e interrogativa) - revisão.

- Presente progressivo revisão. VOCABULÁRIO:

- Ampliação vocabular de verbos;

- Ampliação vocabular de profissões.

GÊNERO

\section{DISCURSIVO:}

Descrição de atividades de rotina (História Narrativa).

- GÊNERO DISCURSIVO:

- Descrição de atividades de rotina (História Narrativa).

Espera-se que ao completar o $1^{\circ}$ bimestre os alunos desenvolvam as seguintes habilidades:

- Usar o Presente Simples em diversas situações comunicativas;

- Reconhecer as diferenças entre verbos no presente simples e no presente progressivo;

- Compreender e usar estruturas do Presente Simples em diversas situações comunicativas;

- Usar negação no Presente Simples para falar de ações diárias e rotinas;

- Usar expressões de tempo relacionadas ao presente;

- Produzir uma história pessoal (relato) com atividades diárias.

Mesmo para um jovem de 11 anos em média, depois de 2 anos de estudos de língua inglesa, o recorte acima evidencia novamente o foco gramatical. Em relação ao exemplo anterior do $5^{\circ}$ ano, o cerne do bimestre acima é ainda mais estrutural e sistêmico, pois há a constante menção de tempos verbais apenas. De novo, uma criança de 11 ou 12 anos está no início da adolescência, portanto as atividades não deveriam ser tão infantilizadas, nem tampouco tão abstratas com o foco apenas do ensino sistêmico de uma língua. 
Leituras ou jogos de raciocínio, jogos de tabuleiro, pegadinhas de raciocínio, contar piadas e conversas com perguntas quebra gelo são sugestões que estão relacionadas com a vida que se vive (MARX \& ENGELS, 2006) contemporânea dessa faixa etária. Como já citado anteriormente, o conteúdo proposto nesse currículo do $7^{\circ}$ ano poderia estar de alguma forma relacionado com as atividades sociais sugeridas por Liberali (2012), ou seja, fazer passeios (museu, parque, zoológico etc.), fazer compras, ler revistas em quadrinhos.

Repetidamente, os itens do currículo apresentado não possibilitam instrumentos discursivos para que as idiossincrasias da superdiversidade (VERTOVEC, 2007), da complexidade e da multiculturalidade da vida que se vive (MARX \& ENGELS, 2006) contemporânea possam ser vivenciadas, expandidas, mudadas, questionadas, transformadas.

Para evidenciar esse enfoque gramatical, mesmo para o $9^{\circ}$ ano, com jovens de 14 e 15 anos, segue o recorte do $1^{\circ}$ bimestre:

\begin{tabular}{|c|c|c|}
\hline & $\begin{array}{l}\text { CONTEÚDOS DO } 9^{\circ} \text { ANO } \\
\text { DE LÍNGUA INGLESA }\end{array}$ & HABILIDADES \\
\hline 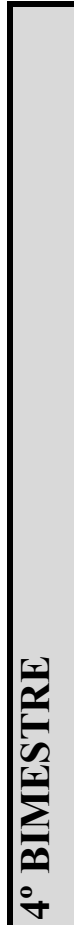 & $\begin{array}{l}\text { GRAMÁTICA } \\
\text { - Uso de just, already e } \\
\text { yet; } \\
\text { - Presente perfeito + ever } \\
\text { e never. } \\
\text { VOCABULÁRIO: } \\
\text { - Vocabulário sobre } \\
\text { arquitetura e obras de } \\
\text { arte; } \\
\text { - Vocabulário de tipos de } \\
\text { dança; } \\
\text { - Verbos no particípio } \\
\text { passado. } \\
\text { GÊNERO } \\
\text { DISCURSIVO: } \\
\text { Letras de música. }\end{array}$ & $\begin{array}{l}\text { - Compreender e usar vocabulário relacionado à } \\
\text { temática abordada; } \\
\text { - Reconhecer e usar os pronomes interrogativos em } \\
\text { diversas situações comunicativas; } \\
\text { - Reconhecer e usar ever em perguntas no Presente } \\
\text { Perfeito; } \\
\text { - Usar just, already e yet com o Presente Perfeito em } \\
\text { diversas situações comunicativas; } \\
\text { - Utilizar o gênero Letras de Música para aquisição } \\
\text { do léxico e de outras estruturas relacionadas ao uso } \\
\text { do Presente Perfeito. }\end{array}$ \\
\hline
\end{tabular}

Um pré-adolescente de 14 ou 15 anos já manifesta inclinação para a futura profissão. Muitos deles até já ingressam no mercado de trabalho. No mais, também gostam de usar as redes sociais, a Internet de modo geral, ouvir música alta, ir ao 
shopping, sair em grupos, dentre outras atividades. No entanto, mesmo no último bimestre do ensino fundamental II, o currículo acima evidencia novamente o foco no 'estudo' do sistema da língua inglesa, pois a presença de itens estruturais sistêmicos é constante: pronomes interrogativos, aquisição do léxico, particípio passado etc. Há, no entanto, o trabalho com letras de música, o que de uma maneira está relacionado com o mundo os pré-adolescentes. Porém, mesmo assim, as letras de músicas parecem ser desculpas para se adquirir itens lexicais e 'outras estruturas do uso do presente perfeito'. Como já discutido previamente, as sugestões de Liberali (2012) no que dizem respeito às atividades sociais do $9^{\circ}$ ano, ou seja, conhecer outras culturas (pela Internet), discutir problemas com amigos, assistir a filmes, dentre outras, poderiam ser as diretrizes docentes para a organização dessa matriz curricular.

Tendo como base as discussões de Liberali (2016), a matriz curricular poderia ser organizada a partir do conceito da atividade social, já citado previamente, cuja finalidade é estabelecer relações dos conteúdos aprendidos na escola com as necessidades que a vida impinge para uma participação mais ativa.

De novo, as atividades propostas acima apresentadas não propiciam relações com as atividades da vida que se vive (MARX \& ENGELS, 2006) contemporâneas dessa faixa etária, do $9^{\circ}$ ano. As atividades reais desse grupo seguem incólumes, céleres, com distâncias abissais em relação ao que a escola propõe como programa de ensino, que é descontextualizado, estrutural, puramente sistêmico.

\section{Considerações finais}

De modo geral, os três modelos de currículos apresentados falham ao propiciar ferramentas educativas e culturais adequadas, principalmente linguísticas, de modo que qualifique e capacite os alunos para interagir no mundo de uma forma mais contundente, protagonistica e crítica, muito menos terem pleno domínio da leitura e da escrita, do cálculo e do raciocínio, como apregoa o citado documento oficial municipal. Os recortes apresentados evidenciam a falta mínima de se desenvolver ferramentas de leitura, quiçá artefatos culturais que poderiam instrumentalizar e capacitar os alunos para realizar, participar, expandir, mudar, questionar, transformar as novas atividades humanas impingidas por mundo cada vez mais complexo, superdiverso (VERTOVEC, 2007) e multicultural.

Certamente, esses são apenas pequenos recortes de um contexto específico e de uma disciplina em particular. Outros estudos são necessários, em outros contextos e com outras disciplinas para que essa incompatibilidade de gênios entre os modelos escolares e a vida que se vive (MARX \& ENGELS, 2006) contemporânea possa ser ainda mais investigada a fim de que se possam propiciar reflexões sobre os alunos que a escola está formando, baseado em documentos oficiais. 
Os modelos apresentados, com os saberes encapsulados (LIBERALI, 2015, 2016), evidenciam a concepção daltônica e monocultural, discutida por Candau (2011), que ofusca o papel da escola na subversão dos contextos superdiversos, repletos de zonas de desconforto e diferenças sociais. Com essa conduta monocultural (CANDAU, 2011), a escola na verdade reforça e perversidade da globalização, discutida anteriormente por Santos (2000), pois com o status quo mantido, não há chances de emergir novas forças na sociedade. Não há espaços onde artefatos culturais condizentes com as peculiaridades do mundo modernos possam ser desenvolvidos de modo que a diversidade possa ser discutida, respeitada vivenciada e consequentemente a criatividade possa ser aguçada e construída. Também não há espaços para uma prática docente mais libertadora, provedora de instrumentos culturais e multimodais de ação ativa na sociedade, de espaços para a ascensão social mais democrática.

Os exemplos dos currículos apresentados também suscitam reflexões sobre as ações docentes e de formação de professores, de modo que essas particularidades do mundo moderno se façam presentes na pauta do ambiente escolar de forma mais veemente. Se nada for repensado no que diz respeito à ação pedagógica, a incompatibilidade de gênios entre o modelo escolar e a 'vida que se vive' contemporânea pode ser ainda mais contundente, o que pode arrebatar a força da globalização no seu sentido perverso e algoz, como discutido por Santos (2000).

Sendo assim, dada a incompatibilidade de atuações das duas circunstâncias tanto da vida que se vive contemporânea e dos modelos escolares, entende-se que é imperativo que a escola construa urgentemente modelos de ação docentes que tenham afinidades com a realidade, com a vida do jeito que ela é, para que compatibilidades possam ser estabelecidas e assim os alunos terem condições melhores e espaços de atuação mais protagonística no mundo contemporâneo superdiverso (VERTOVEC, 2007).

\section{Referências bibliográficas}

BLOMMAERT, J. 2013. Citizenship, language and superdiversity: towards complexity. Journal of Language, Identity and Education, v. 12, n. 2, p. 193-196.

. 2013. Ethnography, Superdiversity and Linguistic Landscapes:

Chronicles of Complexity. Bristol, UK: Multilingual Matters.

BURBULES, N.C \& TORRES, C.A. 2004. "Globalização e Educação: perspectivas críticas" Porto Alegre, Editora Artmed, pp. 11 - 25.

CANDAU, V.M. F \& ANHORN, C.T.G. 2012. A questão didática e a perspectiva multicultural: uma articulação necessária. 
CELANI, A. A. 2001. Ensino de línguas estrangeiras: ocupação ou profissão?, IN: LEFFA, V. J. O professor de Línguas Estrangeiras construindo a profissão. Pelotas: Educat. pp. 21-39.

ESTEFOGO, F. 2005. Atividades de Planejar: espaços de formação e atuação crítica. Tese de Doutorado. PUCSP.

Mestrado. PUCSP.

2001. Reflexão Crítica: caminhos para novas ações. Dissertação de

FERREIRA, A. J. (org). 2014. As Políticas do Livro Didático e Identidades Sociais de Raça, Gênero, Sexualidade e Classe em Livros Didáticos. Campinas, SP: Pontes Editoras.

FREIRE, P. 2003. Educação e mudança. São Paulo: Paz e Terra. . 1970. Pedagogia do Oprimido. São Paulo: Paz e Terra.

GARCIA, O. \& FLORES, NELSON. 2012. Multilingual Pedagogies. In: The Routledge handbook of multilingualism / edited by Marilyn Martin-Jones, Adrian Blackledge and Angela Creese. London: Routledge.

LEFFA, Vilson J. 2014. Língua estrangeira: ensino e aprendizagem. Pelotas: Educat, 2016.

.; IRALA, Valesca Brasil (Orgs.). Uma espiadinha na sala de aula: ensinando línguas adicionais no Brasil. Pelotas: Educat.

2012. Ensino de línguas: passado, presente e futuro. Revista de Estudos da Linguagem. Vol. 20, n. 2, p. 389-411, jul/dez.

. 2002. O ensino de línguas estrangeiras nas comunidades virtuais. In: IV SEMINÁRIO DE LÍNGUAS ESTRANGEIRAS, 2001, Goiânia. Anais do IV Seminário de Línguas Estrangeiras. Goiânia: UFG, v. 1, p. 95-108.

- 2001. Aspectos políticos da formação do professor de línguas estrangeiras. In: LEFFA, Vilson J. (Org.). O professor de línguas estrangeiras; construindo a profissão. Pelotas, v. 1, p. 333-355.

LIBERALI, F. C. 2016. Inglês: linguagem em atividades sociais. São Paulo: Blucher, V. 2.

. 2016. A reflexão e a prática no ensino. São Paulo: Blucher. V. 2.

et al. 2015. Projeto digit-m-ed Brasil: uma proposta de desencapsulação da aprendizagem escolar por meio dos multiletramentos. Revista Prolíngua, Volume 10 - Número 3,

. 2013. Argumentação em contexto escolar. Campinas. Pontes: 2009. Atividade Social nas aulas de língua estrangeira. São Paulo:

Moderna.

2004. As linguagens das reflexões, IN: MAGALHÃES, M.C.C (org.). A linguagem na formação de professores como profissionais reflexivos críticos. São Paulo: Mercado de Letras. 
. \& ZYNGIER, S. 2000. Caderno de Reflexões. Rio de Janeiro.

Serviço de Publicações da UFRJ.

MAGALHÃES, M.C. C \& CELANI, M.A.A. 2001. Reflective sessions: a tool for Teacher empowerment. Paper apresentado na conferência Genres and Discourses in Education, Work and Cultura Life. Oslo, Noruega, de 13 a 16 de maio de 2001.

MARX, K.; ENGELS, F. 2006. A ideologia alemã: seguido das Teses sobre Feuerbach. 9. ed. Trad. Sílvio D. Chagas. São Paulo: Centauro.

SANTOS, M. 2000. Por outra globalização - do pensamento único à consciência universal. São Paul: Record.

VERTOVEC, S. 2007. Super-diversity and its implications. Ethnic and Racial Studies, v. 29 , n. $6,1-42$.

Francisco ESTEFOGO holds Ph.D. (2005) and Master (2001) degrees in Applied Linguistics from the Catholic University of São Paulo. He's currently a postdoctorate researcher in reflective teaching at PUCSP. He's also the Coordinator of Faculdade Cultura Inglesa and Academic Director of Cultura Inglesa Taubate. He's been involved with English teaching for over 20 years. His main areas of interest include learning strategies, critical reflection, teacher training, socio-constructivism, agency etc. E-mail: franestefogo@uol.com.br 